Article

\title{
Personalized UV Radiation Risk Monitoring Using Wearable Devices and Fuzzy Modeling
}

\author{
Paraskevas Tsantarliotis ${ }^{1,2}$, Markos G. Tsipouras ${ }^{1,3,4}$ and Nikolaos Giannakeas 1,3,* \\ 1 Q Base R\&D, Science \& Technology Park of Epirus, University of Ioannina Campus, GR45110 Ioannina, \\ Greece; paris.tsantarliotis@gmail.com (P.T.); tsipouras@qbase.gr (M.G.T.); giannakeas@qbase.gr (N.G.) \\ 2 Department of Computer Science \& Engineering, University of Ioannina, GR45110 Ioannina, Greece \\ 3 Department of Computer Engineering, School of Applied Technology, Technological Educational Institute of \\ Epirus, Kostakioi, GR47100 Arta, Greece; tsipouras@teiep.gr \\ 4 Department of Informatics and Telecommunications Engineering, University of Western Macedonia, \\ GR50100 Kozani, Greece; mtsipouras@uowm.gr \\ * Correspondence: giannakeas@teiep.gr; Tel.: +30-6937-222157
}

Received: 26 March 2018; Accepted: 18 April 2018; Published: 20 April 2018

\begin{abstract}
This paper presents a solution for monitoring of solar ultraviolet (UV) exposure and alerting about risks in real time. The novel system provides smart personalized indications for solar radiation protection. The system consists of a sensing device and a mobile application. The sensing device monitors solar radiation in real time and transmits the values wirelessly to a smart device, in which the mobile application is installed. Then, the mobile application processes the values from the sensory apparatus, based on a fuzzy expert system (FES) created from personal information (hair and eye color, tanning and burning frequency), which are entered by the user answering a short questionnaire. The FES provides an estimation of the recommended time of safe exposure in direct sunlight. The proposed system is designed to be portable (a wearable sensing device and smartphone) and low cost, while supporting multiple users.
\end{abstract}

Keywords: UV radiation; UV sunlight; personalized healthcare; fuzzy expert system; monitoring systems

\section{Introduction}

Sunlight is the electromagnetic energy given off by the Sun and plays a very important role for the life on our planet. Practically, life on our planet cannot be sustained without sunlight. It consists of infrared, visible and ultraviolet (UV) radiation. From the perspective of maximum safe exposure levels, UV radiation is the most aggressive spectral region. It constitutes about $10 \%$ of the total light output of the Sun and its wavelength varies from 10-400 nm [1,2]. Even though UV radiation is a part of sunlight, people cannot perceive it directly because this specific wavelength range is blocked by the cornea and the lens of the eye. Furthermore, UV radiation is divided into nine different subtypes based on the wavelength range. The most important of these subtypes are ultraviolet A (UVA) and ultraviolet $B(U V B)$. UVA, which accounts for the vast majority of the UV radiation that reaches the surface of Earth, penetrates the skin more deeply than UVB, and it is the dominant tanning ray. On the other hand, UVB is the main cause of skin reddening and sunburn.

Exposure to direct sunlight, and thus to UV radiation, is known to have many positive effects on our health, such as vitamin D synthesis, blood pressure decreases and antidepressant effects [3]. However, excessive exposure to sunlight can cause serious health complications [4]. UV radiation is related to various skin cancers, of which melanoma is the most life-threatening [5]. Additional skin health conditions are also a result of prolonged exposure to solar radiation, such as photoageing [6] and cataracts [7]. 
The effects of UV radiation on our health depend on the color of our skin. According to [8], there are six different types of skin (also known as the Fitzpatrick scale) based on how the skin reacts to UV radiation. Type I describes pale white skin that always gets sunburnt, whereas Type VI describes deeply pigmented dark skin that never gets sunburnt. It is known that fairer skin is more vulnerable to UV radiation, which means that it is more likely to be burned or get skin cancer [9]. Darker skin seems to be more UV resistant due to increased levels of melanin in the skin. It does not get sunburned or skin cancer as quickly as fairer skin types, but it is not immune either. Consequently, no matter our skin color, we must take the necessary precautions against $U V$ radiation.

The most direct way to be protected from the Sun is to apply sunscreen to any uncovered areas of the body. However, applying sunscreen to the body works for a limited amount of time, based on each person's individual profile (skin color, hair color, and so on) [10]. When that amount of time is exceeded, the protection is limited, and the sunscreen dosage must be re-applied. Other suggested methods include the use of sunglasses, light-colored clothes and hats when under direct sunlight, and so on.

As awareness of the subject increase, people become accustomed to the idea that skin must be protected, and they seek more innovative ways of protection as they are not entirely prepared to abandon the idea of sunbathing (mainly due to the domestic implications associated with sun exposure such as tanning, but also due to other reasons that include health reasons such as the metabolism of vitamin D). Most people are aware of the dangers associated with sun exposure [11], thus measuring and evaluating such exposure can be a very useful tool in their lives. For example, it would be very useful for families who prefer a fair amount of exposure for their children, but also want a tailor-made method to measure the exposure and be alerted when certain thresholds are met to re-apply sunscreen. In addition, individuals who are concerned about the health state of the skin of their face and body may want a definitive method to measure their exposure and minimize the risk of direct Sun contact at any time.

In this work, we propose a system that provides smart indications for protection from solar radiation. The goal of this system is to fill the gap of personal protection from sunlight in an innovative way by calculating a personalized index of solar hazards associated with the user and the surrounding environment. Our system has four main characteristics. Firstly, it is portable so users can carry it with them at all times. It is also customizable so it can support multiple users. Moreover, it provides accurate measurements of the UV radiation, and finally, it is affordable. The system consists of two main parts: a sensing device, which measures the solar radiation in real time, and an application, which processes the values from the sensory apparatus. The user provides significant information about himself/herself and his/her sensitivity to solar radiation by answering a few easy questions. The application processes the user characteristics and the data regarding the solar radiation and provides an estimation of the recommended time of safe exposure in direct sunlight.

The remainder of this paper is organized as follows. Section 2 reviews work on solar radiation and its health impact and existing work on protection from solar radiation. In Section 3, we provide an overview of the system architecture, and Section 4 contains the experimental evaluation and results. Finally, in Section 5, we discuss our work and conclude the paper.

\section{Related Work}

Ultraviolet radiation has been in the spotlight of the research community for many years. Scientists from different disciplines such as physicists, biologists and medical doctors have tried to understand the effects of sunlight and its radiation on the life on our planet. As we mentioned earlier, the wavelength of UV radiation ranges from $10-400 \mathrm{~nm}$ and is divided into nine different subtypes.

The most widely-known subtypes are UVA (315-400 nm) and UVB (280-315 nm) [1,2], which are considered the two wavelength ranges that cause long-term health issues. Note that some scientists argue that UVB should be separated from UVA at $320 \mathrm{~nm}$; however, this is not a significant factor in the scope of this paper. There is also ultraviolet C $(100-280 \mathrm{~nm})$, which is considered as a much 
more harmful type of UV radiation. Luckily, the ozone layer absorbs UVC completely and about $90 \%$ of UVB [1]. On the contrary, the ozone layer seems to have almost no effect on UVA. In addition, scientists studied the effect of clouds on UV radiation [12] and found out that clouds usually reduce the amount of radiation that reaches the surface of Earth; however, there are cases in which UV radiation is enhanced because of the cloud effect. The altitude also plays a significant role in UV radiation [13], since at higher altitudes, the UV radiation is stronger due to the fact that a thinner atmosphere filters less radiation. In particular, UV levels increase by $10 \%$ every $1000 \mathrm{~m}$.

The hottest topic about UV radiation concerns its implications on the health of humans [14], both short and long term. UV radiation is related to many adverse effects on the skin such as erythema and photoaging [15], as well as immunosuppression [16]. The most serious implication of UV radiation is known to be the main risk factor for many types of skin cancers such as squamous cell carcinoma [17]. To make matters worse, the ozone layer continuously declines over non-polar areas [18].

On the other hand, UV radiation also has positive effects on our health. It can be used to treat skin diseases like vitiligo [19] and psoriasis [20]. The most important benefit of UV radiation is the formation of vitamin D. The "sunshine vitamin" has many positive effects on our health [21]. It can improve calcium absorption and our metabolism [22], leading to stronger bones. Vitamin D can even reduce the risk of certain types of cancer [23]. Furthermore, the lack of vitamin D can cause many health issues. For example, it can affect pregnant and nursing women [24] or increase the risk of cardiovascular diseases [25]. Research has shown that vitamin D produced by the skin lasts much longer in the blood circulation than orally-administered vitamin D [26].

Considering the above, it is essential to regulate our exposure to solar and UV radiation in order to avoid the harmful effects and enjoy the beneficial effects of UV exposure at the same time. To this end, we need tools that can track the exposure and recommend actions or warn us against UV radiation. In the last few years, many applications have hit the market that promise to protect us from UV radiation. For example, UV Lens [27], TANTasticUV [28] and the Wolfram Sun Exposure Reference App [29]. All these provide personalized recommendations in a similar way to our system. However, the main drawback of these applications is that they are not based on real-time UV values. UV is measured by weather stations that are far away from the user's position or it is measured from a forecast. Another interesting idea is the My UV Patch created by L'Oreal [30]. The user attaches a small heart-shaped patch onto his/her skin, which can interact with smart devices using the corresponding app, track the exposure of the user to UV radiation and provide personalized recommendations to avoid sunburns. However, the patch lasts only three to five days, then it must be renewed, which can be rather expensive. In addition, the patch can be used only by one person, which does not make it suitable for families.

\section{Materials and Methods}

In this section, an overview of the system architecture is described, and the process of the hardware and software development is presented. The goal of the system is to be portable, customizable, accurate and affordable. The hardware part consists of the sensing device, which is inexpensive to construct and is as big as the size of a matchbox. On the other hand, the software part of the proposed system consists of a mobile application that operates on Android devices.

\subsection{System Architecture}

The system consists of two main parts: a sensing device that retrieves and transmits information regarding the UV radiation in the surrounding environment and an application for Android devices. The sensing device retrieves the amount of UVA and UVB radiation and sends these values to the smart device via a Bluetooth connection. The sensing device runs on a battery; thus, it is essential that the sensors used on this device be energy efficient, ensuring a long battery life. In addition, the size of the sensing device must be reduced as much as possible in order to achieve high portability. The goal is to create a wearable sensing device that could possibly comply with stylistic trends. For example, 
the device can be a fancy bracelet or pendant or even a stylish key ring. This way, users would carry the device almost everywhere and have access to the system whenever they want.

The application, apart from the radiation values, requires additional information concerning the user characteristics in order to provide customizable recommendations. These characteristics include hair and eye color and the reactions of the user's skin after exposure to direct sunlight, that is sunburn and tanning. Considering that the application runs on a portable device, the required calculations must be feasible with limited resources, and the application should not exhaust the resources of the device, ensuring the normal operation of the device, as well as preserving the battery duration of the smart device.

\subsection{Hardware Development}

In order to achieve these goals, a sensing device that is able to perceive the amount of UV radiation, in particular UVA and UVB radiation, in the surrounding environment was designed. This information is gathered by two sensors, and then, it is transmitted via Bluetooth to a smart device with the mobile app installed. Thus, the two main components of the device are the UV sensors and the Bluetooth transceiver module. However, more parts are required in order to complete the sensing device. In particular, the sensing device consists of the following parts:

- Two UV sensors. The Genicom GUVA-T21GH and GUVB-T21GH sensors were used to measure the UVA and UVB radiation, respectively. Both sensors are highly sensitive and operate with a 1.8-5.5 V constant power supply within -30 and $85^{\circ} \mathrm{C}$. The output of the GUVA-T21GH was from 0-4.5 V, and the output of GUVB-T21GH was from 0-100 $\mathrm{mV}$ (for UV index monitoring).

- A Bluetooth transceiver module, which enables the communication between the sensing device and the smart devices. MDFLY RF-0417C was used, which has a small size $(27 \times 14 \mathrm{~mm})$. The Bluetooth TTL transceiver module designed for RS232 communication with 8 Mbit flash memory and the required $5 \mathrm{~V}$ constant power supply.

- A microcontroller, which is a tiny integrated circuit that converts the output of the UV sensors from analog to digital, which is an Atmel ATtiny45, a low-power 8-bit microcontroller with a 4 KB in-system programmable flash memory.

- Two low power dual operational amplifiers, in order to boost the output of the UV sensors, specifically Taitron LM358M, which can achieve a 100-dB voltage gain and operates from a 3-36 V power supply.

- Resistors, capacitors and notification LEDs.

- A 9 V battery for the power supply. Smaller batteries are also an option; however, a large battery was included in the prototype in order to achieve a long battery life during the development phase.

The blueprint of our sensing device is shown in Figure 1.

The prototype includes a 9-V battery; however, the components of the sensing device operate with a 1.8-5.5-V power supply. Because of this, a voltage regulator (78L05) was used to adjust the power supply. The two UV sensors receive the UV radiation and send two analog signals to the circuit. The signals are then directed to the analog ports of the microcontroller. The microcontroller runs a program written in BASCOM-AVR to convert the analog signals to digital signals with 2-s frequency sampling. Finally, the digital output of the microcontroller is directed to the Bluetooth transceiver module.

In addition to the sensing device, an Android smart device, such as smartphone or tablet, is needed. Such devices are very popular, and almost everybody owns at least one such device. The luminance sensor, which usually comes with many of these devices, is used. The idea is to provide additional information to the user about the environmental conditions, in order to take more precautions, if necessary. Unfortunately, there are devices that do not include luminance sensors or the information is not accessible due to limitations posed by the manufacturer. 


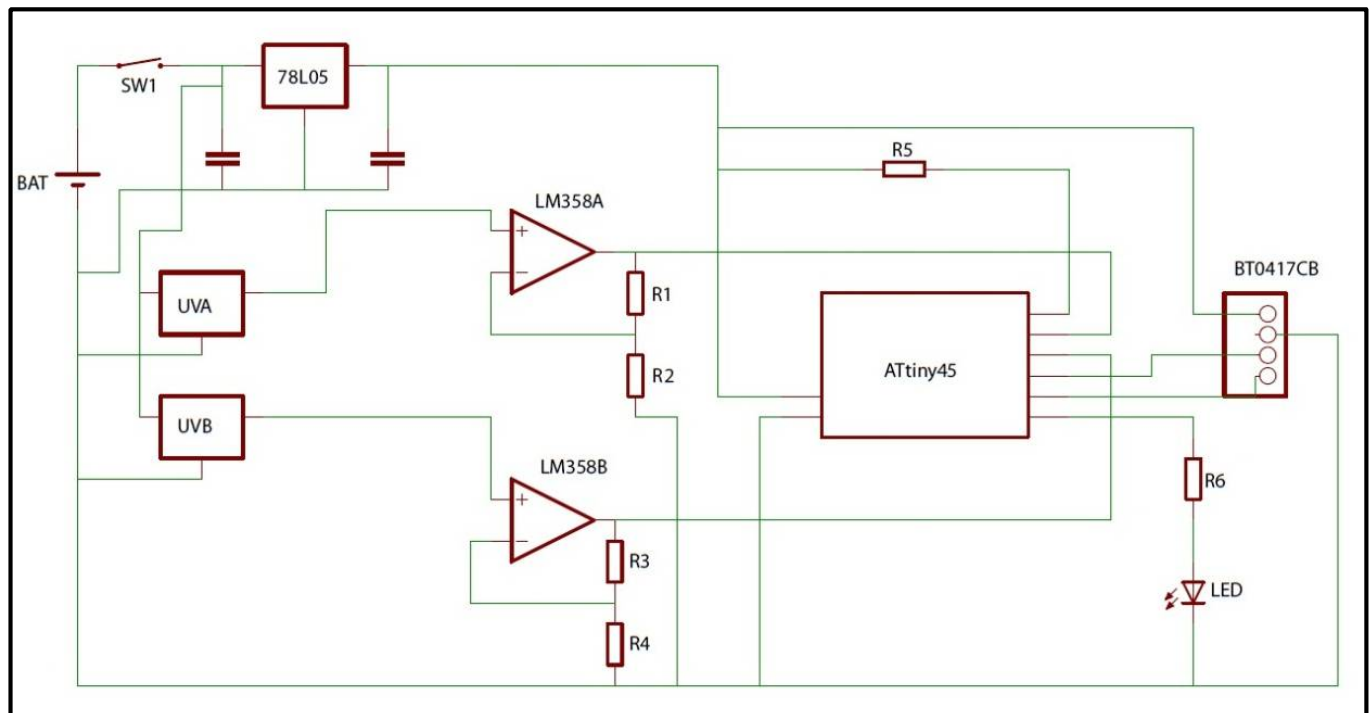

Figure 1. The sensing module blueprint.

\subsection{Mobile App}

The second core part of the proposed system includes an application that runs on Android smart devices. The application is responsible for implementing the interaction between the user and the system. Its goals are to retrieve the information from the sensing device and provide personalized recommendations to the users about the solar hazards. In addition, it can store information for multiple users. Thus, the system can serve a group of people, such as a family, at the same time.

The application is written in Java, and its interface consists of four main tabs (Figure 2). The first tab contains a synopsis of the users and the corresponding safe time period of exposure to sunlight for each user. The safe time frame of exposure to sunlight is defined as the maximum period that a person can be exposed to sunlight without getting his/her skin reddened or burned (in minutes). The minimal sunlight dosage capable of inducing a sunburn on human skin is called the minimal erythemal dose (MED), and it is measured in Joules per square meter [10]. Thus, people can be safely exposed to sunlight, until their skin receives 1 MED [10]. The user's management is achieved through the second tab. The third tab illustrates the obtained information about the solar radiation in the surrounding environment, UV radiation and luminance. Finally, the fourth tab contains information about the sunlight, UV radiation and the application.
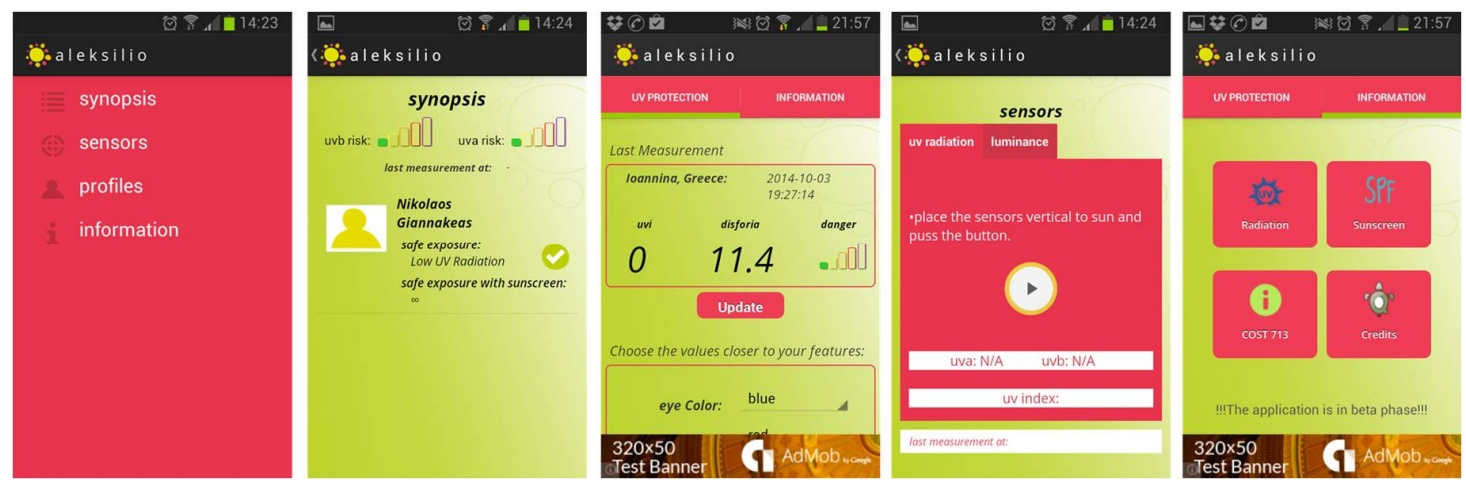

Figure 2. The mobile app's main tabs. From left to right: the opening screen and the four main tabs: the synopsis of the users, users' management, sensors readings and the general information. 


\subsection{Fuzzy Expert System}

The most important part of the application is the personalized recommendations regarding the safety of the user. In particular, the application estimates the users' safe exposure to sunlight. The proposed model is based on the results that are presented in [10], which can be divided into two main parts. The first part concerns the decision about the skin type, and the second part concerns the estimation of the time period of safe exposure to sunlight. Human skin is characterized into four discrete categories based on hair and eye color, whether the skin tans and how often it gets sunburned (Table 1). The safe exposure is estimated based on the skin type and the UV radiation. In addition, the use of sunscreen can extend the safe exposure.

Table 1. The basic skin types for the European population [10]. MED, minimal erythemal dose.

\begin{tabular}{cccccc}
\hline Skin Type & Eye Color & Hair Color & Tanning Frequency & Sun Burning Frequency & 1 MED \\
\hline I & Blue & Red & Never & Always & $200 \mathrm{~J} / \mathrm{m}^{2}$ \\
II & Blue/Green & Blond & Sometimes & Sometimes & $250 \mathrm{~J} / \mathrm{m}^{2}$ \\
III & Gray/Brown & Brown & Always & Rarely & $350 \mathrm{~J} / \mathrm{m}^{2}$ \\
IV & Brown/Black & Black & Always & Never & $450 \mathrm{~J} / \mathrm{m}^{2}$ \\
\hline
\end{tabular}

The goal is to calculate the duration of safe exposure for each user. Because of this, a multi-layered fuzzy model with three distinct layers was created. The first layer concerns the user characteristics, and it is responsible for deciding the skin type of the user. It consists of a multi-input to multi-output (MIMO) fuzzy model, which takes four input variables (i.e., tanning frequency, sun burning frequency, hair color and eye color) as inputs and outputs four values, one for each skin type. The fuzzy membership functions were defined as Cauchy functions:

$$
f_{s}(x)=\frac{1}{1+\left|\frac{x-c_{x, s}}{a_{x, s}}\right|^{2 b_{x, s}}}
$$

with $x$ being the input variable and, thus, $x=$ \{tanning frequency, sun burning frequency, hair color, eye color $\}, s$ being the skin type and, thus, $s=\{I, I I, I I I, I V\}$, and the $a_{x, s}, b_{x, s}$ and $c_{x, s}$ parameters defining the shape of each function. To define the values of the $a_{x, s}, b_{x, s}$ and $c_{x, s}$ parameters, initially, a discrete rating scale for each input variable was defined (Table 2).

Table 2. Discrete rating scales for the input variables.

\begin{tabular}{llll}
\hline Tanning Frequency & Sun Burning Frequency & Hair Color & Eye Color \\
\hline 0: Never & 0: Never & 0: Red & 0: Blue \\
1: Rarely & 1: Rarely & 1: Red-Blond & 1: Blue/Green \\
2: Sometimes & 2: Sometimes & 2: Blond & 2: Green \\
3: Often & 3: Often & 3: Blond-Brown & 3: Green/Gray \\
4: Always & 4: Always & 4: Brown & 4: Gray \\
& & 5: Brown-Black & 5: Gray/Brown \\
& & 6: Black & 6: Brown \\
& & 7: Brown/Black \\
& & 8: Black \\
\hline
\end{tabular}

Based on the values of Table 1 and the discrete rating scales (Table 2), the $c_{x, s}$ parameter is defined. Based on the values of the $c_{x, s}$ parameter, the distance between consecutive skin types for the same input variable was defined:

$$
d_{x, s_{i}, s_{i+1}}=\left\{\begin{array}{cc}
0.5 & \text { if }\left|c_{x, s_{i}}-c_{x, s_{i+1}}\right| \leq 1 \\
1 & \text { if }\left|c_{x, s_{i}}-c_{x, s_{i+1}}\right| \leq 2 \\
2 & \text { else }
\end{array}\right.
$$


where $s_{i}, s_{i+1}$ are two consecutive skin types and $d_{x, s_{i}, s_{i+1}}$ is their distance for a specific input variable $x$. Then, the values of the $a_{x, s}$ parameter are defined based on the distance:

$$
a_{x, s_{i}}=\left\{\begin{array}{cc}
d_{x, s_{i}, s_{i-1}} & \text { if } d_{x, s_{i}, s_{i-1}}=d_{x, s_{i}, s_{i+1}} \\
\frac{d_{x, s_{i}, s_{i-1}}+d_{x, s_{i}, s_{i+1}}}{2} & \text { else }
\end{array}\right.
$$

Finally, the $b_{x, s}$ parameter is set to three as a constant to all fuzzy membership functions. The values of the $a_{x, s}, b_{x, s}$ and $c_{x, s}$ parameters are presented in Table 3.

Table 3. Values for the $\left\{a_{x, s}, b_{x, s}, c_{x, s}\right\}$ parameters.

\begin{tabular}{ccccc}
\hline Skin Type & Tanning Frequency & Sun Burning Frequency & Hair Color & Eye Color \\
\hline I & $\{1,3,0\}$ & $\{1,3,4\}$ & $\{1,3,0\}$ & $\{0.5,3,0\}$ \\
II & $\{1,3,2\}$ & $\{0.75,3,2\}$ & $\{1,3,2\}$ & $\{1.25,3,1\}$ \\
III & $\{0.75,3,4\}$ & $\{0.5,3,1\}$ & $\{1,3,4\}$ & $\{2,3,5\}$ \\
IV & $\{0.5,3,4\}$ & $\{0.5,3,0\}$ & $\{1,3,6\}$ & $\{2,3,8\}$ \\
\hline
\end{tabular}

Based on the values of Table 3, the fuzzy membership functions were defined and are illustrated in Figure 3.
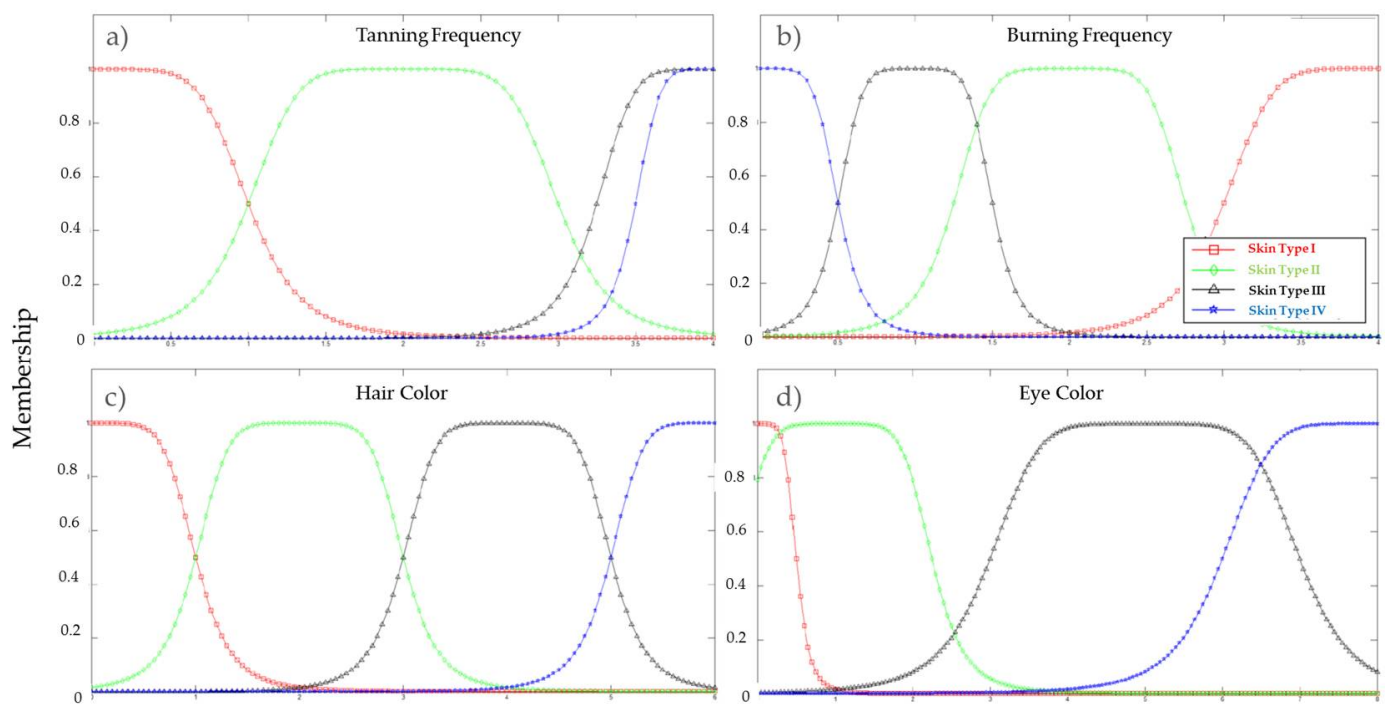

Figure 3. The fuzzy membership functions for tanning frequency (a), sun burning frequency (b), hair color (c) and eye color (d), for skin types I, II, III and IV, with red, green, blue and black, respectively.

The output of the first layer is a matrix defined as:

$$
V=\left\{u_{x, s}\right\}=\frac{f_{s}(x)}{\sum_{s} f_{s}(x)}
$$

where $\sum_{s} f_{s}(x)$ is a normalization factor.

The second layer is responsible for estimating the user's duration of safe exposure. This time, we used a multi-input to single-output (MISO) fuzzy model, which takes the fuzzy values from the previous layer $(V)$ and the information about the UV radiation as an input and outputs the duration of the safe exposure of the user (Figure 4). The UV radiation is measured with the UV index (UVI); thus, we convert the GUVB-T21GH sensor output values to UVI. 


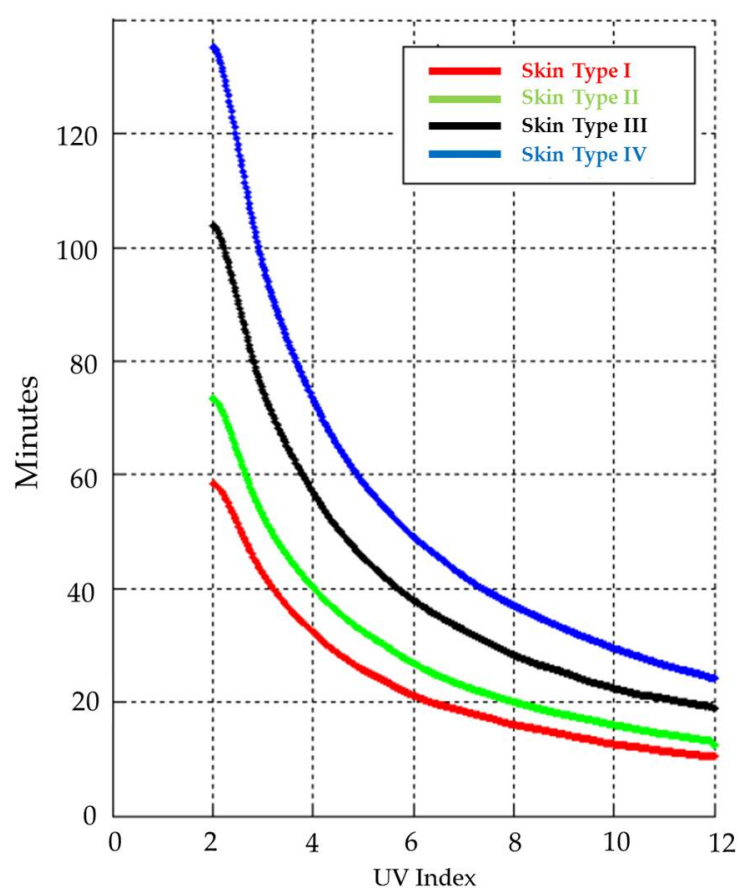

Figure 4. The sunburn times in minutes for skin types I, II, III, and IV and 1 minimal erythemal dose (MED) [10].

By applying the UVI in the above figure, a vector of time values is defined as the intersection points with the UVI value (that is, a vertical line):

$$
t=\left\{t_{s}^{U V I}\right\}
$$

Finally, the third layer combines the safe exposure of the user with the information regarding the sunscreen that he/she uses and recalculates the duration of the safe exposure. This is done through a defuzzification function:

$$
T=\frac{1}{4}\left\|V t^{\prime}\right\|_{1}=\frac{1}{4} \sum\left(V t^{\prime}\right)=\frac{1}{4} \sum_{x}\left(\sum_{s} u_{x, s} t_{s}^{U V I}\right)
$$

The sun protection factor (SPF) of the sunscreen multiplies the time of safe exposure:

$$
T_{S}=\operatorname{spf} \times T
$$

For example, consider a user with $10 \mathrm{~min}$ of safe exposure using a sunscreen with $15 \mathrm{SPF}$, then his/her new duration of safe exposure is $150 \mathrm{~min}$.

\section{Evaluation and Results}

In this section, an extensive evaluation of the proposed system is performed. The evaluation can be considered a two-phase process. At first, the accuracy of the values received by the sensing device is validated, and then, testing scenarios with real users are conducted.

\subsection{Sensing Device Evaluation}

The first thing that we had to validate was the accuracy of the UV values retrieved by the sensing device. This is the most important step in the evaluation of our system because inaccurate UV values would lead to invalid conclusions and potentially harm the users of our system. We created two different scenarios to test the application. During the first scenario, we compared measurements 
of the sensing device with the corresponding ones of another source, whereas in the second scenario, we tested whether the distance between the sensing device and the mobile device affects the measurements.

\subsubsection{UV Radiation Measurements}

To validate the accuracy of the sensing device, a comparison of the UV values retrieved from the device with the values retrieved from a large weather station that belongs to the Laboratory of Meteorology of the Department of Physics of the University of Ioannina (UoI) was conducted. The weather station is located at the university and tracks the weather conditions all through the day. Additional sensors for UV measurements are installed (KIPP \& ZONEN UV-S-A-T and UV-S-B-T). The data that were retrieved from the weather station contained information about the exact time of the measurement (year, month, day, hour and minute), the values about UV radiation (UVA, UVB and UVI) and some additional information (such as the radiant flux received by a surface per unit area). For the scope of this work, only the information about the UVI was used.

The evaluation dataset contains UVI values from two five-day periods. During the first period, the UVI was recorded from 10:00 in the morning to 15:00, whereas during the second period, it was measured from 15:00-19:00. In both periods, the sampling frequency was set to five minutes. During the recordings, the sensing device was positioned to directly face the sun. The obtained values for the two five-day recording periods are illustrated in Figure 5.

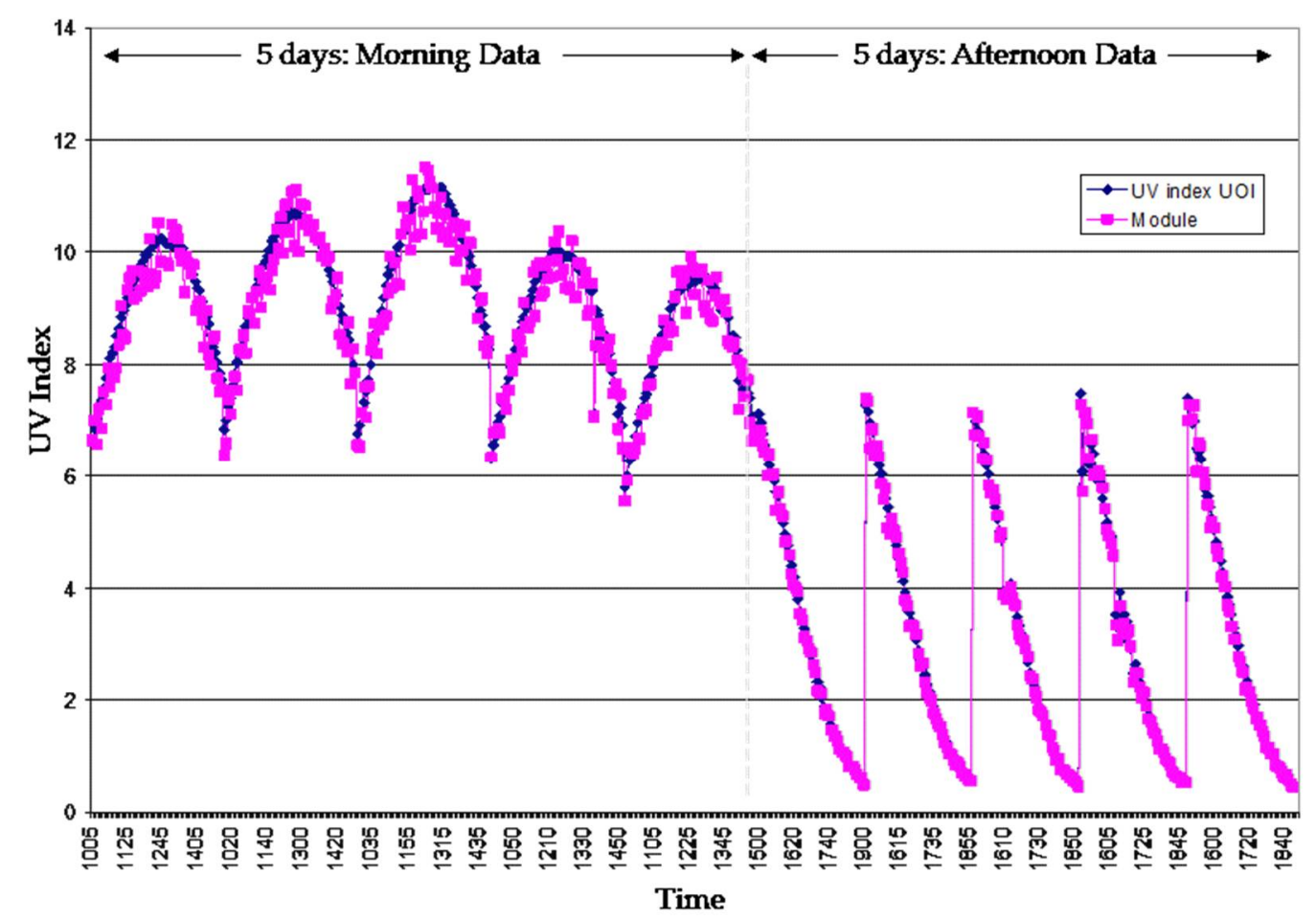

Figure 5. The UV index (UVI) data obtained from a ground-truth station (UV index University of Ioannina (UOI)) and the sensing device (module).

In order to evaluate the data, the square error for each sample was calculated:

$$
\text { Square Error }=\left(U V I_{U O I}-U V I_{\text {Module }}\right)^{2},
$$

and the result for each sample is presented in Figure 6. The mean square error value for the morning data (that is, from 10:00-15:00) is 0.1347 (with a 0.3165 mean absolute error), while the mean square error value for the afternoon data (that is, 15:00-19:00) is 0.0325 (with a 0.1555 mean absolute error). 


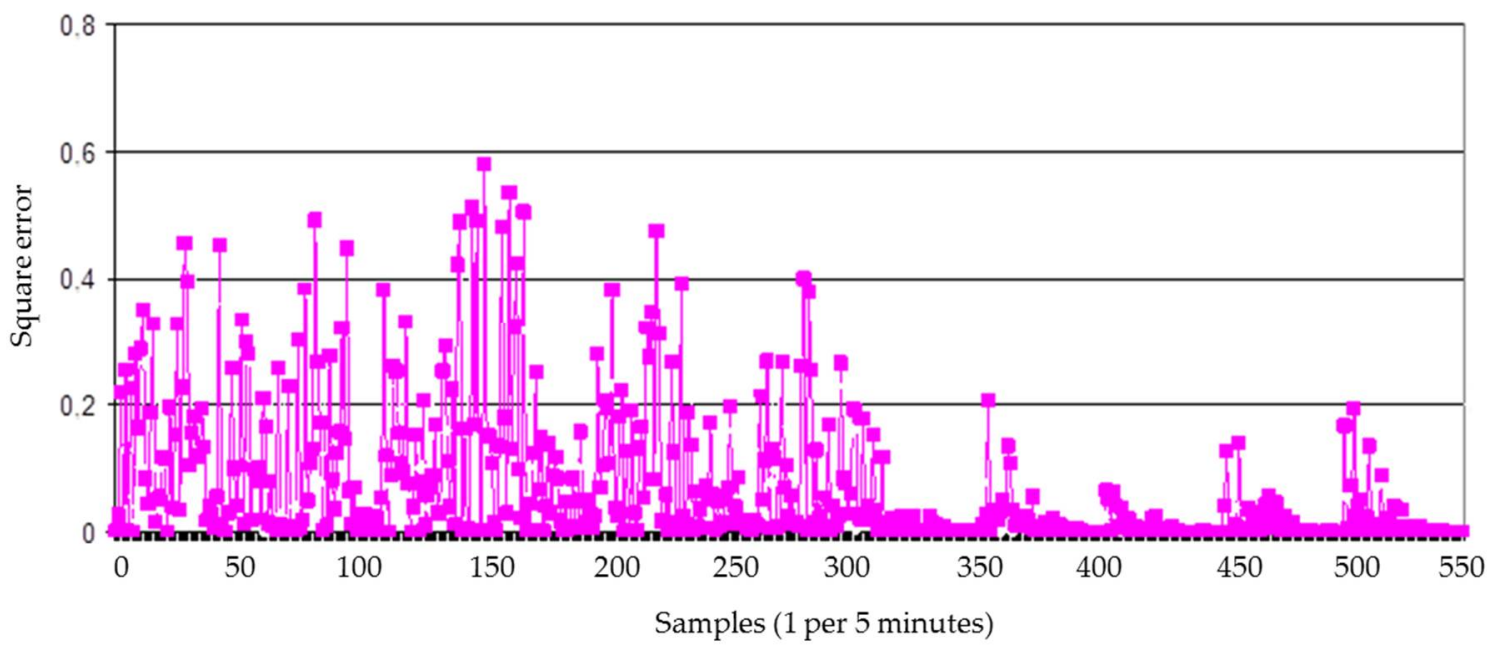

Figure 6. UVI Square error for each sample.

\subsubsection{Broadcast Coverage}

The broadcast range of the device was also evaluated and whether the distance between the sensing module and the smart device affects the UV values reported. To this end, we marked the outdoor place with a starting point and the additional points every two meters. The sensing device remained at the starting point for the whole duration of the test. A tester used the smart device to record the UVI values and the distance beginning from the starting point and moving to the next point every two minutes. The tester stopped when the smart device could not receive values from the sensing device.

The above process was repeated one hundred times on different days and different hours of the day. The broadcast range of the sensing device ranged from 10-12 $\mathrm{m}$. This was expected since this is the maximum range of the Bluetooth module declared by the manufacturer. Furthermore, there was no indication that the broadcasted UV values from the sensor are affected by the distance. The sensing device in each iteration broadcasted the same values in each repeat until the tester was out of range. However, it is shown that the range of the sensing device was slightly reduced as the number of trials was increased. We attribute this to the battery drainage, and it is something that requires further investigation, especially if we want to reduce the power of the battery. In Figure 7, we can see the broadcast range of the sensing device (in meters) for each trial.

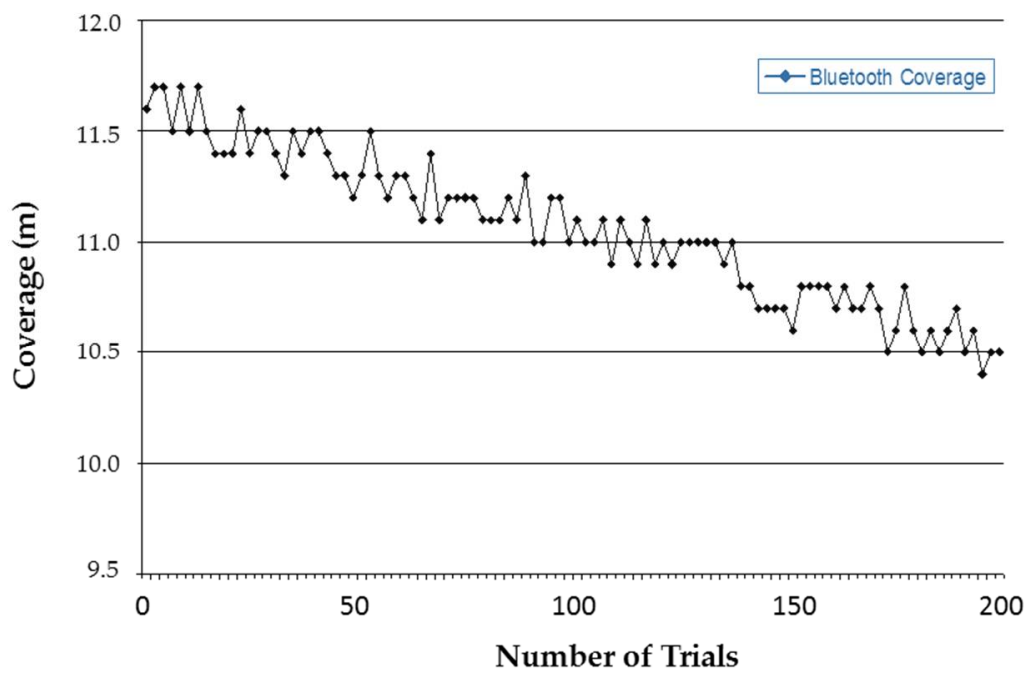

Figure 7. The distance that the module communicates with mobile devices (coverage) for each trial. 


\subsection{Real User Testing}

After the evaluation of the sensing module, the system was tested in real case scenarios with real users. The goal of this test was to investigate whether the proposed system works correctly at generating safe exposure times that do not cause any problems for the users. Twenty-three volunteers participated, and their profiles are presented in Table 4.

The evaluation protocol for each user was the following:

- The user had a short training session on the system usage.

- The user created his/her own profile in the system.

- The user completed several (2-6) testing sessions of the system. In each session:

- $\mathrm{He} / \mathrm{she}$ used the system to get a UVI value and a proposed exposure time (based on his/her profile).

- Then, the user remained exposed to direct sunlight for the proposed time. During this period, parts of his/her upper body (such as the torso, arms and shoulders) were uncovered in order to have a better understanding of the effects of UV radiation.

- After the safe exposure time frame expired, the user covered his/her body, and further exposure to sunlight was avoided.

- After a few hours, the users reported on their skin condition (sunburn).

Table 4. The user profiles regarding eye and hair color, as well as tanning and burning frequencies.

\begin{tabular}{|c|c|c|c|c|}
\hline User ID & Eye Color & Hair Color & Tanning Frequency & Burning Frequency \\
\hline 1 & brown & brown & never & always \\
\hline 2 & brown-black & brown & rarely & rarely \\
\hline 3 & green-grey & black & never & always \\
\hline 4 & blue-green & black & often & never \\
\hline 5 & grey-brown & brown & always & rarely \\
\hline 6 & grey & red-blond & sometimes & always \\
\hline 7 & blue-green & blond-brown & sometimes & never \\
\hline 8 & grey & black & sometimes & sometimes \\
\hline 9 & black & blond & rarely & always \\
\hline 10 & green-grey & brown-black & often & often \\
\hline 11 & grey & blond & sometimes & often \\
\hline 12 & black & black & always & rarely \\
\hline 13 & brown & brown-black & sometimes & rarely \\
\hline 14 & brown-black & brown-black & often & sometimes \\
\hline 15 & brown & brown & often & rarely \\
\hline 16 & brown & blond & often & sometimes \\
\hline 17 & green & blond & always & often \\
\hline 18 & green-grey & blond & sometimes & sometimes \\
\hline 19 & black & brown-black & often & never \\
\hline 20 & brown & brown & never & always \\
\hline 21 & brown-black & brown & rarely & rarely \\
\hline 22 & green-grey & black & never & always \\
\hline 23 & blue-green & black & often & never \\
\hline
\end{tabular}

This phase lasted about two months, starting from early August when the UV values are considerably high, and each user completed up to six sessions during this period. The phase was constantly supervised by the research team, that is the users never used the system alone or remained exposed to sunlight for more or less than the safe exposure time frame. Note, all users were advised to immediately abandon the tests in the case of any type of discomfort. For this phase, the data collected from 105 sessions completed by the users are presented in Table 5. 
Table 5. The results from the sessions in real subjects.

\begin{tabular}{|c|c|c|c|c|c|c|c|c|c|c|c|}
\hline $\begin{array}{l}\text { User } \\
\text { ID }\end{array}$ & $\begin{array}{c}\text { UV } \\
\text { Index }\end{array}$ & $\begin{array}{l}\text { Exposure } \\
\text { Time (min) }\end{array}$ & $\begin{array}{l}\text { Sun } \\
\text { Burn }\end{array}$ & $\begin{array}{l}\text { User } \\
\text { ID }\end{array}$ & $\begin{array}{c}\text { UV } \\
\text { Index }\end{array}$ & $\begin{array}{l}\text { Exposure } \\
\text { Time (min) }\end{array}$ & $\begin{array}{l}\text { Sun } \\
\text { Burn }\end{array}$ & $\begin{array}{l}\text { User } \\
\text { ID }\end{array}$ & $\begin{array}{c}\text { UV } \\
\text { Index }\end{array}$ & $\begin{array}{l}\text { Exposure } \\
\text { Time (min) }\end{array}$ & $\begin{array}{l}\text { Sun } \\
\text { Burn }\end{array}$ \\
\hline \multirow[t]{4}{*}{1} & 5.57 & 37 & None & \multirow[t]{4}{*}{9} & 6.95 & 30 & None & \multirow[t]{2}{*}{16} & 7.91 & 33 & None \\
\hline & 3.81 & 55 & None & & 6.80 & 34 & None & & 5.5 & 51 & None \\
\hline & 3.64 & 57 & None & & 3.92 & 58 & None & \multirow[t]{5}{*}{17} & 4.01 & 37 & None \\
\hline & 8.24 & 25 & None & & 5.99 & 38 & None & & 7.92 & 27 & None \\
\hline \multirow[t]{4}{*}{2} & 3.52 & 47 & None & \multirow[t]{6}{*}{10} & 3.16 & 52 & None & & 7.25 & 30 & None \\
\hline & 8.87 & 18 & None & & 8.09 & 20 & None & & 5.05 & 43 & None \\
\hline & 3.34 & 49 & None & & 4.33 & 38 & None & & 4.89 & 45 & None \\
\hline & 4.57 & 36 & None & & 4.52 & 36 & None & \multirow[t]{5}{*}{18} & 6.21 & 37 & None \\
\hline \multirow[t]{2}{*}{3} & 9.46 & 19 & None & & 7.89 & 21 & None & & 5.00 & 46 & None \\
\hline & 6.92 & 26 & None & & 3.41 & 48 & None & & 4.22 & 54 & None \\
\hline \multirow[t]{5}{*}{4} & 7.09 & 27 & None & \multirow[t]{5}{*}{11} & 9.06 & 22 & None & & 8.55 & 26 & None \\
\hline & 6.69 & 28 & None & & 4.09 & 49 & None & & 8.01 & 28 & None \\
\hline & 4.50 & 42 & None & & 8.62 & 23 & None & \multirow[t]{4}{*}{19} & 3.89 & 58 & None \\
\hline & 9.73 & 19 & Light & & 9.62 & 21 & None & & 5.03 & 45 & None \\
\hline & 5.06 & 38 & None & & 6.66 & 30 & None & & 3.72 & 61 & None \\
\hline \multirow[t]{6}{*}{5} & 5.10 & 36 & None & \multirow[t]{6}{*}{12} & 9.77 & 21 & None & & 4.26 & 53 & None \\
\hline & 4.31 & 42 & None & & 7.80 & 27 & None & \multirow[t]{5}{*}{20} & 3.86 & 51 & None \\
\hline & 3.03 & 59 & None & & 4.58 & 46 & None & & 8.18 & 24 & None \\
\hline & 7.08 & 26 & None & & 4.07 & 51 & None & & 4.05 & 49 & None \\
\hline & 4.91 & 37 & None & & 5.46 & 38 & None & & 4.23 & 47 & None \\
\hline & 3.61 & 50 & None & & 8.27 & 25 & None & & 5.38 & 37 & None \\
\hline \multirow[t]{3}{*}{6} & 4.01 & 52 & None & \multirow[t]{4}{*}{13} & 7.39 & 24 & None & \multirow[t]{5}{*}{21} & 6.79 & 27 & None \\
\hline & 4.98 & 42 & None & & 9.08 & 20 & Light & & 5.53 & 33 & None \\
\hline & 3.01 & 69 & None & & 3.76 & 48 & None & & 5.55 & 33 & None \\
\hline \multirow[t]{6}{*}{7} & 8.01 & 24 & None & & 8.11 & 22 & None & & 4.34 & 42 & None \\
\hline & 4.31 & 42 & None & \multirow[t]{5}{*}{14} & 4.67 & 45 & None & & 3.26 & 55 & None \\
\hline & 3.03 & 59 & None & & 5.90 & 36 & None & \multirow[t]{3}{*}{22} & 3.50 & 50 & None \\
\hline & 7.08 & 26 & None & & 4.07 & 52 & None & & 4.76 & 37 & None \\
\hline & 4.91 & 37 & None & & 5.91 & 36 & None & & 3.03 & 58 & None \\
\hline & 3.61 & 50 & None & & 9.25 & 23 & Light & \multirow[t]{7}{*}{23} & 9.40 & 28 & None \\
\hline \multirow[t]{6}{*}{8} & 4.04 & 60 & None & \multirow[t]{6}{*}{15} & 3.45 & 50 & None & & 9.44 & 28 & None \\
\hline & 8.57 & 28 & None & & 3.48 & 49 & None & & 8.69 & 30 & None \\
\hline & 4.08 & 59 & None & & 3.81 & 45 & None & & 6.29 & 42 & None \\
\hline & 7.92 & 30 & None & & 7.73 & 22 & None & & 3.90 & 68 & None \\
\hline & & & & & 3.31 & 52 & None & & 9.91 & 26 & None \\
\hline & & & & & 4.96 & 35 & None & & & & \\
\hline
\end{tabular}

Based on the real-use data, the system presents excellent efficiently in proposing the same sunlight exposure time against UV radiation, since only three cases (2.86\%) of sunburn were reported and were all light cases. These cases can be attributed to two main reasons: the specific users were too sensitive to UV radiation and that the UVI value increased shortly after the measurement was taken, which would lead to a measurably less safe exposure time frame. The latter case is very important and needs to be further investigated, especially in the time periods when the UVI is rapidly increasing.

\section{Discussion}

A personalized approach for estimating the risk of UV radiation, using wearable devices and mobiles applications, is proposed. The system consists of a prototype wearable device, along with a mobile application. Such a system could be very important for sensitive users in sunlight, especially in sunny countries during summer. The main innovation of the system is the fuzzification of the Cost 713 parameters in order to provide accurate exposure times regarding the characteristics of each user.

According to the results, the personalized exposure time estimation for different users seems to be accurate, since only a few cases presented with light sunburn. The comparison between the UV index provided by the proposed system and the Meteo Station of the University of Ioannina also indicate a high accuracy of the measurements. The assessment of sunburn, which is provided by the users 
themselves, could be noticed as the main disadvantage of the evaluation protocol. Finally, further experiments could be provided in order to investigate if the system underestimates the exposure time.

Currently, the wearable device is a prototype version (as described in Section 3.2) and using a 9-V battery; thus, it is not optimized in terms of wearability. Several improvements have been designed for the final versions of both the hardware of the module and the software components. Rapidly developed hardware technologies that the proposed system uses provide the opportunity to optimize the system regarding coverage, autonomy, size, shape and wearability. The final wearable device has been designed to be the size of commercial wristbands, with Bluetooth Low Energy communication and a rechargeable battery using a micro USB cable. Furthermore, the mobile application could be expanded to gather data from external sources (that is, real-time UV measurements for the current position of the user). Prognosis of the UV index can also be retrieved from external sources for better notifications about future conditions. Concerning the research, the proposed system has to be tested in a larger number of subjects, especially in persons who are very sensitive to sunlight exposure.

Acknowledgments: The project was partly funded by the project 44NEWE2009 entitled "Smart system for the protection of UV solar radiation" funded by the action "Support of new enterprises for research and technological development", in cooperation with the Greek General Secretariat of Research and Technology.

Author Contributions: Nikolaos Giannakeas and Markos G. Tsipouras conceived of the idea. Paraskevas Tsantarliotis developed the software components including the module connectivity and mobile app. Nikolaos Giannakeas designed and developed the hardware of the wearable prototype. Markos G. Tsipouras implemented the fuzzy expert system for the personalization of the module. All three prepared the manuscript.

Conflicts of Interest: The authors declare no conflict of interest.

\section{References}

1. World Health Organization (WHO). Global Solar UV Index: A Practical Guide, Report (Geneva: WHO). Available online: http:/ / www.who.int/uv/publications/en/UVIGuide.pdf (accessed on 28 January 2018).

2. ISO 21348 Definitions of Solar Irradiance Spectral Categories. Available online: http:/ /www.spacewx.com/ pdf/SET_21348_2004.pdf (accessed on 28 January 2018).

3. Juzeniene, A.; Moan, J. Beneficial effects of UV radiation other than via vitamin D production. Dermato-Endocrinology 2012, 4, 109-117. [CrossRef] [PubMed]

4. Reichrath, J. The challenge resulting from positive and negative effects of sunlight: How much solar UV exposure is appropriate to balance between risks of vitamin D deficiency and skin cancer? Prog. Biophys. Mol. Biol. 2006, 92, 9-16. [CrossRef] [PubMed]

5. Siegel, R.L.; Miller, K.D.; Jemal, A. Cancer Statistics, 2018. CA Cancer J. Clin. 2018, 68, 7-30. [CrossRef] [PubMed]

6. Wlaschek, M.; Tantcheva-Poór, I.; Naderi, L.; Ma, W.; Schneider, L.A.; Razi-Wolf, Z.; Schüller, J.; Scharffetter-Kochanek, K. Solar UV irradiation and dermal photoaging. J. Photochem. Photobiol. B Biol. 2001, 63, 41-51. [CrossRef]

7. Linetsky, M.; Raghavan, C.T.; Johar, K.; Fan, X.; Monnier, V.M.; Vasavada, A.R.; Nagaraj, R.H. UVA light-excited kynurenines oxidize ascorbate and modify lens proteins through the formation of advanced glycation end products: Implications for human lens aging and cataract formation. J. Biol. Chem. 2014, 289, 17111-17123. [CrossRef] [PubMed]

8. Fitzpatrick, T.B. The Validity and Practicality of Sun-Reactive Skin Types I through VI. Arch. Dermatol. 1988, 124, 869-871. [CrossRef] [PubMed]

9. D'Orazio, J.; Jarrett, S.; Amaro-Ortiz, A.; Scott, T. UV Radiation and the Skin. Int. J. Mol. Sci. 2013, 14, 12222-12248. [CrossRef] [PubMed]

10. Vanicek, K.; Frei, T.; Litynska, Z.; Schmalwieser, A. UV-Index for the Public; A Guide for Publication and Interpretation of Solar UV Index Forecasts for the Public Prepared by the Working Group 4 of the COST-713 Action "UV-B Forecasting"; European Cooperation in the Field of Scientific and Technical Research: Brussels, Belgium, 2000. 
11. Seite, S.; Del Marmol, V.; Moyal, D.; Friedman, A.J. Public primary and secondary skin cancer prevention, perceptions and knowledge: An international cross-sectional survey. J. Eur. Acad. Dermatol. Venereol. 2017, 31, 815-820. [CrossRef] [PubMed]

12. Calbó, J.; Pages, D.; González, J.-A. Empirical studies of cloud effects on UV radiation: A review. Rev. Geophys. 2005, 43. [CrossRef]

13. McKenzie, R.L.; Johnston, P.V.; Smale, D.; Bodhaine, B.A.; Madronich, S. Altitude effects on UV spectral irradiance deduced from measurements at Lauder, New Zealand, and at Mauna Loa Observatory, Hawaii. J. Geophys. Res. Atmos. 2001, 106, 22845-22860. [CrossRef]

14. Juzeniene, A.; Brekke, P.; Dahlback, A.; Andersson-Engels, S.; Reichrath, J.; Moan, K.; Holick, M.; Grant, W.; Moan, J. Solar radiation and human health. Rep. Prog. Phys. 2011, 74. [CrossRef]

15. Laga, A.C.; Murphy, G.F. The translational basis of human cutaneous photoaging: On models, methods, and meaning. Am. J. Pathol. 2009, 174, 357-360. [CrossRef] [PubMed]

16. Murphy, G.M. Ultraviolet radiation and immunosuppression. Br. J. Dermatol. 2009, 161, 90-95. [CrossRef] [PubMed]

17. Leiter, U.; Claus, G. Epidemiology of melanoma and nonmelanoma skin cancer-the role of sunlight. Sunlight, vitamin D and skin cancer. Adv. Exp. Med. Biol. 2008, 624, 89-103. [CrossRef] [PubMed]

18. Ball, W.T.; Alsing, J.; Mortlock, D.J.; Staehelin, J.; Haigh, J.D.; Peter, T.; Tummon, F.; Stübi, R.; Stenke, A.; Anderson, J.; et al. Evidence for a continuous decline in lower stratospheric ozone offsetting ozone layer recovery. Atmos. Chem. Phys. 2018, 18, 1379-1394. [CrossRef]

19. Westerhof, W.; Nieuweboer-Krobotova, L. Treatment of vitiligo with UV-B radiation vs. topical psoralen plus UV-A. Arch. Dermatol. 1997, 133, 1525-1528. [CrossRef] [PubMed]

20. Tanew, A.; Radacovich-Fijan, S.; Schemper, M.; Hönigsmann, H. Narrowband UV-B phototherapy vs. photochemotherapy in the treatment of chronic plaque-type psoriasis: A paired comparison study. Arch. Dermatol. 1999, 135, 519-524. [CrossRef] [PubMed]

21. Wacker, M.; Holick, M.F. Sunlight and Vitamin D: A global perspective for health. Dermato-Endocrinology 2013, 5, 51-108. [CrossRef] [PubMed]

22. Holick, M.F. The role of vitamin D for bone health and fracture prevention. Curr. Osteoporos. Rep. 2006, 4, 96-102. [CrossRef] [PubMed]

23. Grant, W.B. An estimate of premature cancer mortality in the US due to inadequate doses of solar ultraviolet-B radiation. Cancer 2002, 94, 1867-1875. [CrossRef] [PubMed]

24. Yu, C.K.H.; Sykes, L.; Sethi, M.; Teoh, T.G.; Robinson, S. Vitamin D deficiency and supplementation during pregnancy. Clin. Endocrinol. 2009, 70, 685-690. [CrossRef] [PubMed]

25. Gouni-Berthold, I.; Krone, W.; Berthold, H.K. Vitamin D and cardiovascular disease. Curr. Vasc. Pharmacol. 2009, 7, 414-422. [CrossRef] [PubMed]

26. Haddad, J.G.; Matsuika, L.Y.; Hollis, B.W.; Hu, Y.Z.; Wortsman, J. Human plasma transport of vitamin D after its endogenous synthesis. J. Clin. Investig. 1993, 91, 2552-2555. [CrossRef] [PubMed]

27. UVLens-UV Index Forecasts. Available online: https:/ /uvlens.en.aptoide.com/ (accessed on 28 January 2018).

28. Wolfram Group LLC, Wolfram Sun Exposure Reference App. Available online: http://products. wolframalpha.com/referenceapps/sunexposure.html (accessed on 28 January 2018).

29. Paper Street, Inc., TANtastic UV. Available online: https://itunes.apple.com/gr/app/tantastic-uv/ id700877167? $=$ el\&mt=8 (accessed on 28 January 2018).

30. L'Oreal, My UV Patch. Available online: http://www.loreal.com/media/press-releases/2016/jan/lorealdebuts-first-ever-stretchable-electronic-uv-monitor (accessed on 28 January 2018).

(C) 2018 by the authors. Licensee MDPI, Basel, Switzerland. This article is an open access article distributed under the terms and conditions of the Creative Commons Attribution (CC BY) license (http://creativecommons.org/licenses/by/4.0/). 